\title{
Dual Function of a Novel Bacterium, Slackia sp. D-G6: Detoxifying Deoxynivalenol and Producing the Natural Estrogen Analogue, Equol
}

\author{
Xiaojuan Gao ${ }^{1,2,3,+}$, Peiqiang Mu ${ }^{1,2,3, \dagger}$, Xunhua Zhu ${ }^{1,2,3}$, Xiaoxuan Chen ${ }^{1,2,3}$, Shulin Tang 1,2,3, \\ Yuting $\mathrm{Wu}^{1,2,3}$, Xiang Miao ${ }^{1,2,3}$, Xiaohan Wang ${ }^{1,2,3}$, Jikai Wen ${ }^{1,2,3}$ and Yiqun Deng ${ }^{1,2,3, * \mathbb{C}}$ \\ 1 Guangdong Provincial Key Laboratory of Protein Function and Regulation in Agricultural Organisms, \\ College of Life Sciences, South China Agricultural University, Guangzhou 510642, China; \\ gaoxiaojuan@stu.scau.edu.cn (X.G.); mpeiqiang@scau.edu.cn (P.M.); zhuxunhua@stu.scau.edu.com (X.Z.); \\ xuanzi@scau.edu.cn (X.C.); shulintang@scau.edu.cn (S.T.); 20182003020@stu.scau.edu.cn (Y.W.); \\ xiangmiao@stu.scau.edu.cn (X.M.); xhwang@stu.scau.edu.cn (X.W.); jkwen@scau.edu.cn (J.W.) \\ 2 Key Laboratory of Zoonosis of Ministry of Agriculture, South China Agricultural University, \\ Guangzhou 510642, China \\ 3 Guangdong Laboratory for Lingnan Modern Agriculture, South China Agricultural University, \\ Guangzhou, Guangdong 510642, China \\ * Correspondence: yqdeng@scau.edu.cn; Tel.: +86-20-3860-4967 \\ + These authors contributed equally to this work.
}

Received: 20 December 2019; Accepted: 24 January 2020; Published: 26 January 2020 updates

\begin{abstract}
Deoxynivalenol (DON) is a highly abundant mycotoxin that exerts many adverse effects on humans and animals. Much effort has been made to control DON in the past, and bio-transformation has emerged as the most promising method. However, useful and effective application of bacterial bio-transformation for the purpose of inhibiting DON remains urgently needed. The current study isolated a novel DON detoxifying bacterium, Slackia sp. D-G6 (D-G6), from chicken intestines. D-G6 is a Gram-positive, non-sporulating bacterium, which ranges in size from $0.2-0.4 \mu \mathrm{m} \times 0.6-1.0$ $\mu \mathrm{m}$. D-G6 de-epoxidizes DON into a non-toxic form called DOM-1. Optimum conditions required for degradation of DON are $37-47^{\circ} \mathrm{C}$ and a pH of 6-10 in WCA medium containing $50 \%$ chicken intestinal extract. Besides DON detoxification, D-G6 also produces equol (EQL) from daidzein (DZN), which shows high estrogenic activity, and prevents estrogen-dependent and age-related diseases effectively. Furthermore, the genome of D-G6 was sequenced and characterized. Thirteen genes that show potential for DON de-epoxidation were identified via comparative genomics. In conclusion, a novel bacterium that exhibits the dual function of detoxifying DON and producing the beneficial natural estrogen analogue, EQL, was identified.
\end{abstract}

Keywords: Slackia sp. D-G6; DON; de-epoxidize; equol

Key Contribution: A dual function bacterium, Slackia sp. D-G6, is active in DON detoxification and EQL production. The genome of Slackia sp. D-G6 and potential mechanisms of DON de-epoxidation were analyzed.

\section{Introduction}

Deoxynivalenol (DON) is a mycotoxin that is mainly produced by multiple Fusariums. It contaminates wheat, maize, and other grain crops [1]. DON contamination, which occurs naturally and spontaneously, is highly dependent on climate [2]. Annually, DON causes economic losses in the range of billions of dollars worldwide, by contaminating crops such as wheat and barley [3]. 
DON exerts multiple toxic effects on human and animals. Acute exposure of animals to DON induces abdominal pain, dizziness, headache, throat irritation, nausea, vomiting, diarrhea, and bloody stools [4]. Chronic exposure of animals to DON causes weight loss, anorexia, and nutritional deficiency in animals [5]. The mammalian intestinal tract is a major target of DON. Reportedly, DON impaired the expression of porcine intestinal host defense peptides in weaned piglets, thereby increasing intestinal permeability and significantly decreasing average daily weight gain [6,7]. Additionally, DON targets the innate immune system [8,9]. At the molecular level, many studies have proved that DON may inhibit protein synthesis by interacting with peptidyl transferase, which causes early termination of translation $[10,11]$. Moreover, DON may also activate mitogen activated protein kinases (MAPKs) [12-14], thereby triggering endoplasmic reticulum stress and calcium-mediated signaling [15,16], and/or induce mitochondrial hyperplasia and apoptosis [17,18]. For humans, DON has been classified as a category 3 human carcinogen by the International Agency for Research on Cancer (IARC) [19]. Considering its hazardousness to both humans and animals, the Food and Drug Administration (FDA) has introduced strict limits to levels of DON allowed in foods: $1 \mathrm{ppm}$ for wheat products meant for human consumption, 5-6 ppm on grains or grain byproducts meant for pigs and 10-20 ppm of diets meant for cattle and chicken [3]. Therefore, effective and useful strategies for removing or detoxifying DON are urgently needed, mainly due to the difficulties associated with avoiding contamination by fungi.

Many strategies have been considered for controlling contamination by DON. These include the use of antagonists against DON producing Fusarium spp., [20], cultivation of transgenic crops [21-23], preventing damage to grains during harvest, and maintaining critical factors important for storage. The use of physicochemical detoxifying methods that can be applied post contamination, such as baking, radiating, adsorbing, and acid/alkali treatment have also been considered. However, the effects of fungi contamination control or physicochemical detoxification are very limited. Currently, researchers are increasingly focusing on DON bio-transformation, due to its high efficiency, specificity, and environmental-friendliness. For example, a mixed culture D107 can convert DON into 3-keto-4-deoxynivalenol [24]; the soil bacteria Nocardioides sp. WSN05-2 [25], Sphingomonas S3-4 [26] and Devosia mutans 17-2-E-8 [27] degrade DON into 3-epimer-DON (3-epi-DON); Sphingomonas KSM1 [28] from lake water catabolizes DON into 16-hydroxy-DON (16-HDON). Both 3-keto-4-deoxynivalenol and 3-epi-DON exhibit little toxicity and 16-HDON is 10-fold less phytotoxic to wheat than DON. Importantly, it has been demonstrated that disrupting the C12-13 epoxide, which plays a key role in DON toxicity, was critical for reducing its toxicity [29,30]. Several bacteria capable of DON de-epoxidation, such as Bacillus sp.LS100 from chicken digesta [31], Biomin BBSH797 (also called DSM 11798) from rumen fluid [32], and Eggerthella sp. DII-9 (now revised as Raoultibacter sp. DII-9 based on the latest species classification) from chicken intestine [33] have been identified. However, no genes responsible for de-epoxidation of DON have been identified so far. We suppose that it would be a greater chance to clarify the molecular mechanisms involved based on comparative genomics. Therefore, novel bacteria capable of DON de-epoxidation are required in order to clarify the molecular mechanisms involved and to develop effective DON detoxification methods.

The current study screened and identified a novel bacterium with novel function from chicken intestines that detoxifies DON and transforms daidzein (DZN). Metabolic and genomic characteristics of this strain were investigated and potential genes involved in DON de-epoxidation were analyzed.

\section{Results}

\subsection{Isolating the Bacterium Capable of DON De-Epoxidation from Chicken Intestines}

To isolate the bacterium that converts DON to DOM-1, a modified screening procedure (Figure 1a) was set up based on a previous method [28]. After screening and four passages of the subculture, one single colony, Slackia sp. D-G6 (D-G6), which showed high activity for DON transformation, was 
obtained. HPLC analysis showed that D-G6 completely transformed $25 \mu \mathrm{g} / \mathrm{mL}$ DON to DOM-1 after $48 \mathrm{~h}$ of co-culture (Figure $1 \mathrm{~b}, \mathrm{c}$ ).

a

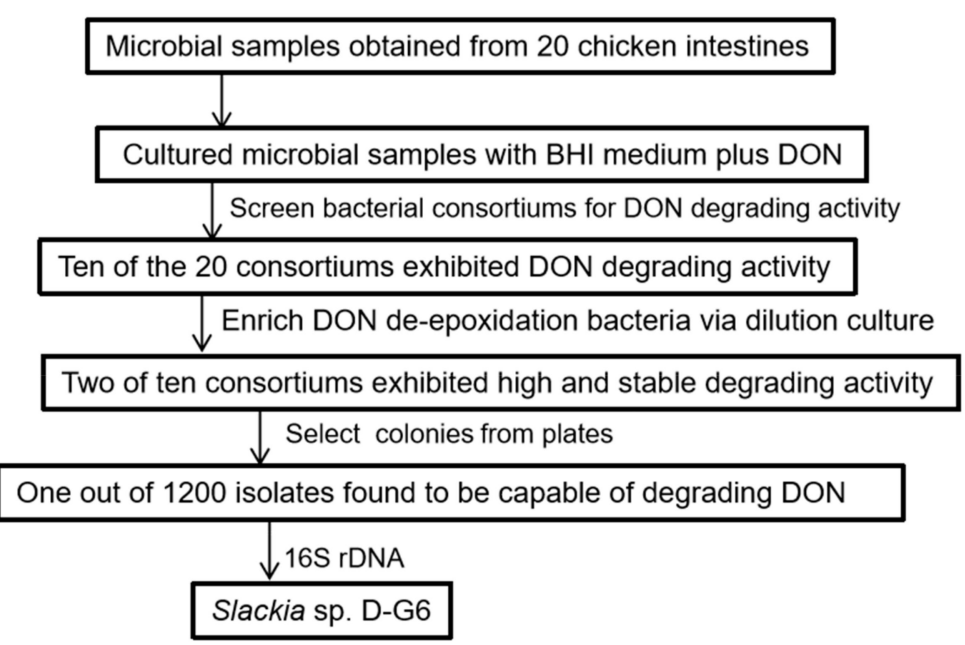

b

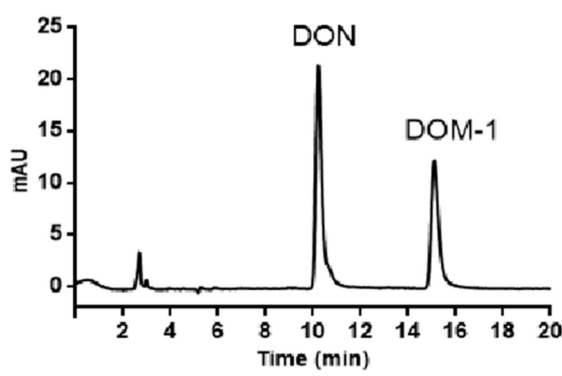

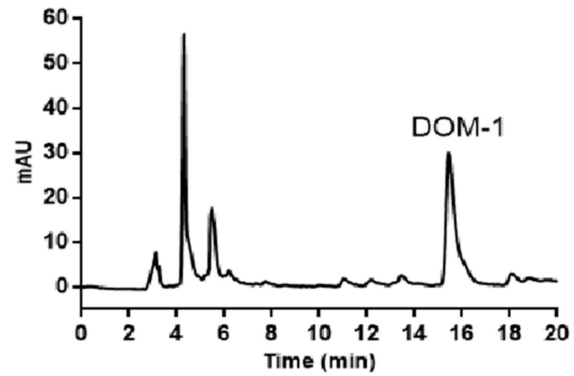

Figure 1. Screening procedure and HPLC analysis of DON and DOM-1 after co-culture of DON with D-G6. (a). Procedure for screening DON transforming bacterium. (b). HPLC chromatography of standard DON and DOM-1. (c). The products of DON transformed by D-G6. DON and DOM-1 standards are indicated at $10.1 \mathrm{~min}$ and $15.6 \mathrm{~min}$, respectively.

\subsection{Identification of the Newly Isolated Bacterium, Slackia sp. D-G6}

To identify the isolate, D-G6, 16S rDNA was sequenced. Nucleotide BLAST using a 16S rDNA sequence, showed that the species phylogenetically closest to D-G6, with a sequence similarity of 99.15\%, was Slackia equolifaciens strain DZE ${ }^{\mathrm{T}}$ (accession no. EU377663). Phylogenetic tree analysis further confirmed that D-G6 was placed in the same cluster that included Slackia species (Figure 2a). We therefore classified DG-6 as a new species of genus Slackia, and named it Slackia sp. D-G6 (D-G6).

The morphology of DG-6 was observed via light microscopy and transmission electron microscopy (TEM). Gram staining indicated that D-G6 was a Gram-positive bacterium (Figure 2b). TEM demonstrated that D-G6 varied in size from $0.2-0.4 \mu \mathrm{m} \times 0.6-1.0 \mu \mathrm{m}$, and was non-sporulating in shape (Figure 2c). 


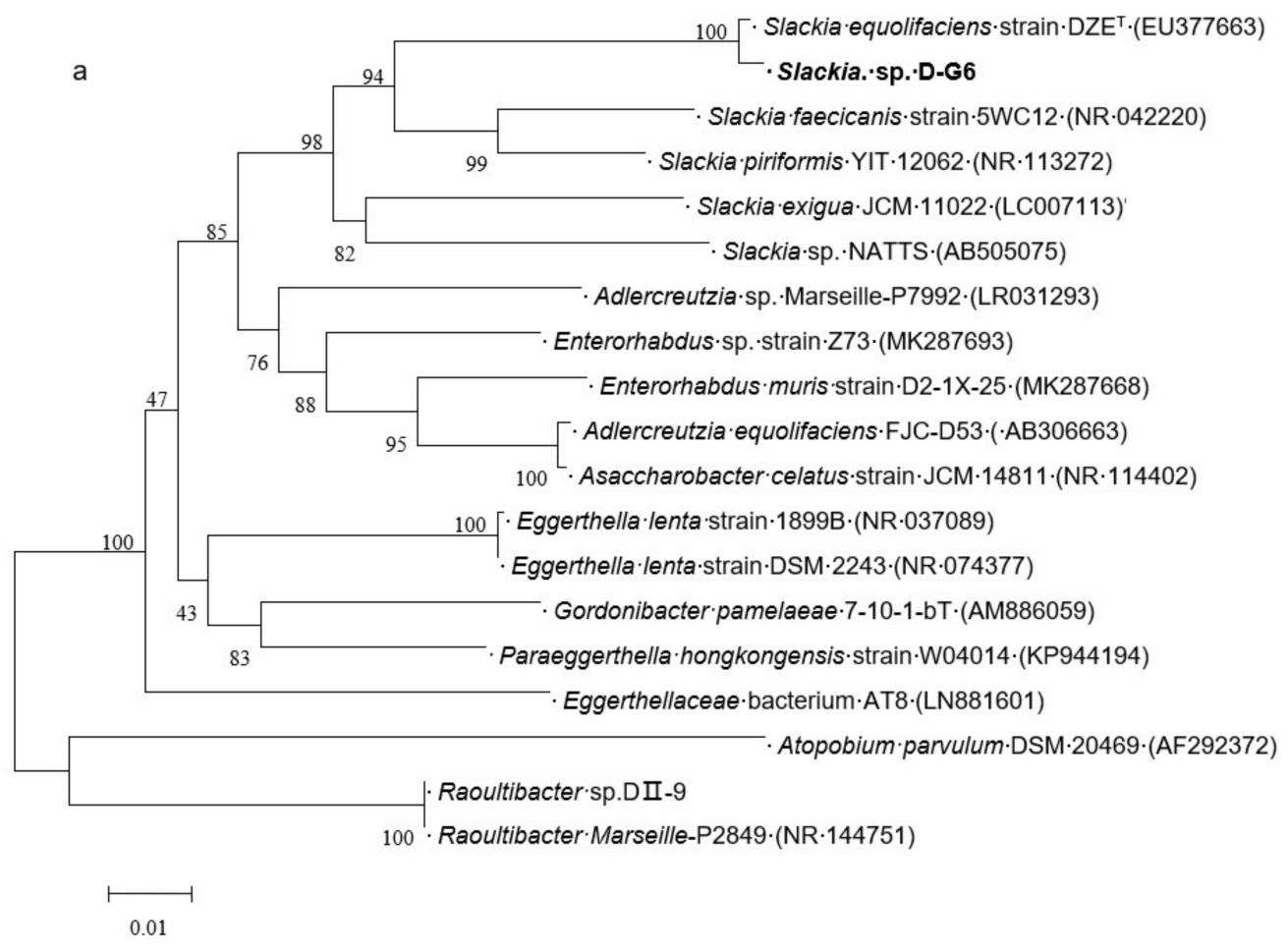

b

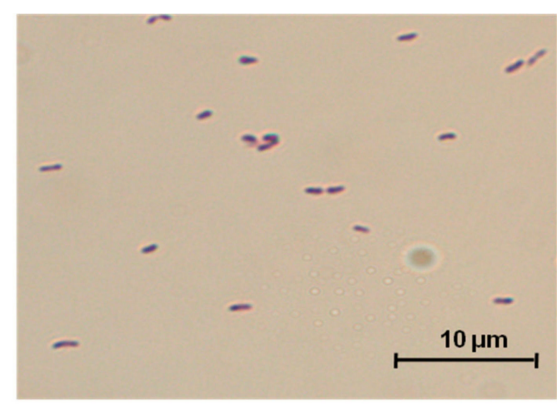

C

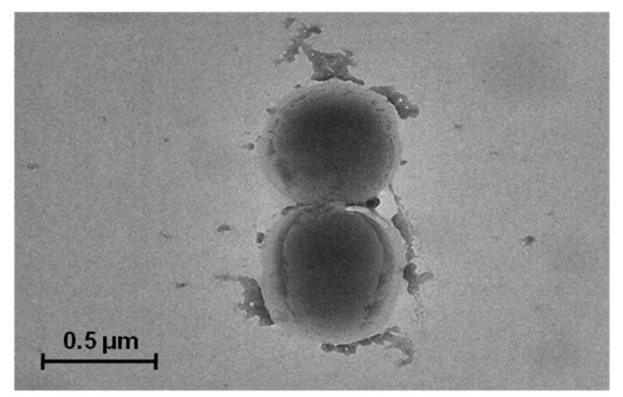

Figure 2. The phylogenetic tree and morphology of Slackia sp. D-G6. (a). The phylogenetic tree of D-G6 based on $16 \mathrm{~S}$ rDNA genes. The GenBank accession numbers of the sequences are shown in parentheses. The bar indicates 0.01 substitutions per nucleotide position. (b). Gram staining of D-G6. (c). Microscopic images of D-G6 under TEM.

\subsection{The Metabolic Characteristics of D-G6}

To investigate the metabolic characteristics of D-G6 that may be involved in transforming DON, the effects of the medium, $\mathrm{pH}$, and temperature on transforming efficiency were analyzed. Firstly, effects of the medium were analyzed. Transforming efficiency was generally low in all tested media, including NB, BHI, GAM, WCA, and TSB, wherein the highest efficiency (approximately 20\%) was observed in WCA (Figure 3a). Interestingly, adding chicken intestine extract (Ext) greatly improved transforming efficiency in all tested media, except GAM (Figure 3b). Especially in WCA medium plus Ext, $25 \mu \mathrm{g} / \mathrm{mL}$ DON was completely transformed to DOM-1 within $48 \mathrm{~h}$ (Figure 3b). Thereby, WCA medium plus Ext was chosen as the optimum medium for D-G6 mediated transformation of DON. Secondly, the effects of temperature were analyzed. D-G6 was active at $32-47^{\circ} \mathrm{C}$ and inactive at $27^{\circ} \mathrm{C}$ and $52^{\circ} \mathrm{C}$ (Figure 3c). Moreover, $25 \mu \mathrm{g} / \mathrm{mL}$ of DON was completely transformed into DOM-1 in $24 \mathrm{~h}$ at $37^{\circ} \mathrm{C}$, and $42{ }^{\circ} \mathrm{C}$ (Figure 3c). Thirdly, the effect of $\mathrm{pH}$ was analyzed. D-G6 was active in $\mathrm{pH}$ values ranging from $5-11$, but showed no activity at $\mathrm{pH} 3$ and 4 , indicating that neutral and basic 
environments were beneficial for DON de-epoxidation (Figure 3d). Finally, the growth and metabolic curves vs. time in WCA medium plus Ext, in pH 6.5, were analyzed. With an inoculation density of approximately $100 \mathrm{CFU} / \mathrm{mL}$, logarithmic growth occurred $24 \mathrm{~h}$ after incubation and reached stationary phase $36 \mathrm{~h}$ later (Figure 3e). However, DON de-epoxidation did not initiate until the growth reached the stationary phase, and DON was completely transformed 3 days after inoculation (Figure 3e). Next, metabolic activity of D-G6 was compared to that of Raoultibacter sp. DII-9 (DII-9) [33]. Under low DON concentrations, the efficacies of D-G6 and DII-9 were comparable, but DII-9 was slightly more efficient than D-G6 when DON concentration was increased (Table 1).

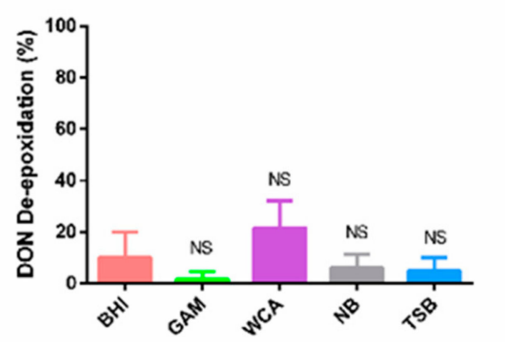

C
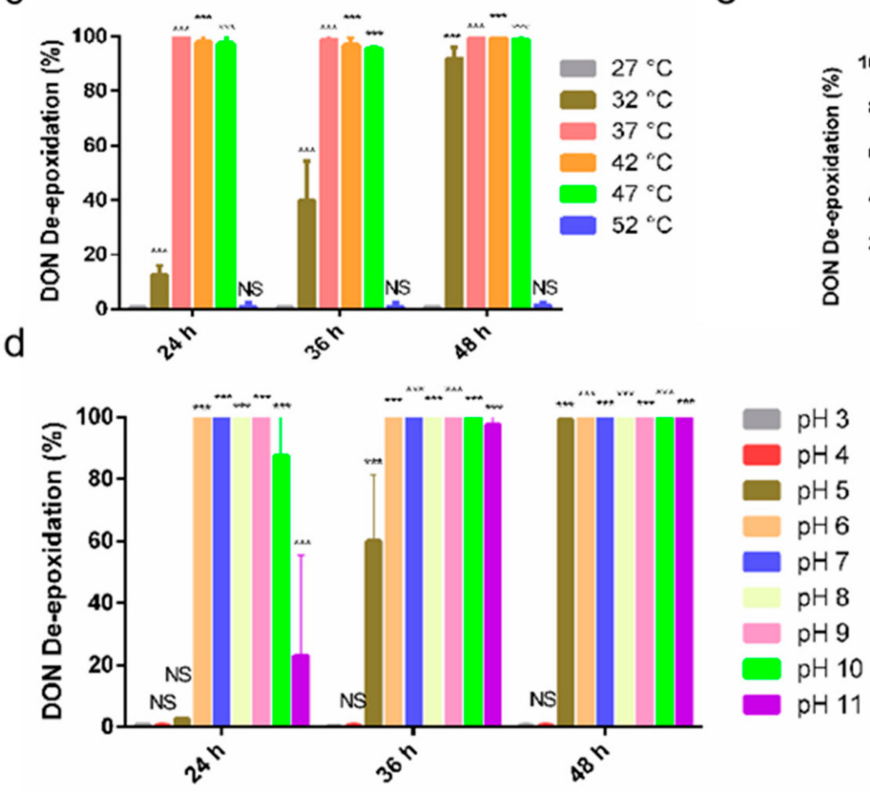

e b
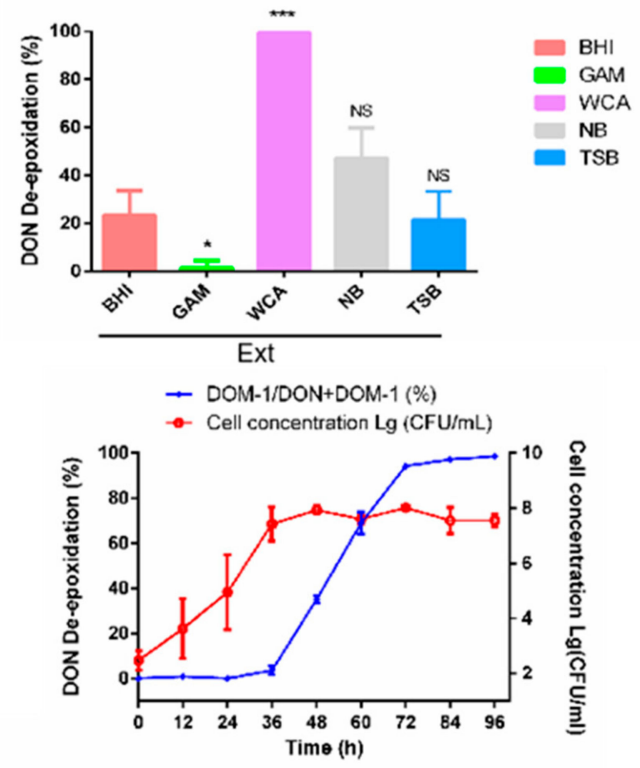

Figure 3. Metabolic characteristics of Slackia sp. D-G6. (a). Transforming efficiency under different media. (b). Transforming efficiency under different medias plus chicken intestine extracts (Ext). (c). The efficiency of DON de-epoxidation of D-G6 at different temperatures. The experiments were performed in WCA modified medium at $\mathrm{pH}$ 6.5. (d). The effects of varying $\mathrm{pH}$ on DON de-epoxidation. The experiments were performed in WCA modified medium and the temperature was set at $37^{\circ} \mathrm{C}$. (e). The growth curve and metabolic curve of D-G6 against time. Inoculation density was approximately $100 \mathrm{CFU} / \mathrm{mL}$, the temperature was $37^{\circ} \mathrm{C}$, and $\mathrm{pH}$ was 6.5. All experiments were replicated three times biologically. The error bars represent the standard deviations. ${ }^{*}$ indicate significantl difference (* $P<0.05$, *** $P<0.001)$, "NS" means "no significance". 
Table 1. Comparison of DON de-epoxidation efficiency between D-G6 and DII-9.

\begin{tabular}{cccc}
\hline \multirow{2}{*}{ DON $(\mu \mathrm{g} / \mathbf{m L})$} & \multirow{2}{*}{ Time (d) } & \multicolumn{2}{c}{ DOM-1/DON+DOM-1 (\%) } \\
\cline { 3 - 4 } & & D-G6 & II-9 \\
\hline \multirow{2}{*}{25} & 1 & 100 & 100 \\
& 2 & 100 & 100 \\
\hline \multirow{2}{*}{75} & 1 & $60-70$ & $80-100$ \\
& 2 & $>95$ & $>95$ \\
\hline \multirow{2}{*}{250} & 1 & $20-35$ & $40-50$ \\
& 2 & $>90$ & $>95$ \\
\hline
\end{tabular}

Note: The concentration of D-G6 or DII-9 were $10^{7}-10^{8} \mathrm{CFU} / \mathrm{mL}$ in $0.2 \mathrm{~mL}$ WCA modified medium. Incubation conditions were as follows: $37^{\circ} \mathrm{C}$ and $\mathrm{pH}$ 6.5. The experiments were repeated at least 3 times independently.

\subsection{Slackia sp. D-G6 is Capable of Producing the Natural Estrogen Analogue, EQL, from DZN}

As most strains of genus Slackia possess the ability to transform DZN to dihydrodaidzein (DHD), tetrahydrodaidzein (THD), or EQL which are beneficial for animal and human health, especially females [34-37], we investigated whether D-G6 was capable of transforming DZN. Three enzymes, daidzein reductase (DZNR), dihydrodaidzein reductase (DHDR), and tetrahydrodaidzein reductase (THDR), involved in DZN transformation were searched against the genome of D-G6, and all three were detected. DZNR, DHDR, and THDR shared an identity of $100 \%, 100 \%$, and $99.4 \%$, respectively, with that of Slackia equolifaciens strain DZE ${ }^{\mathrm{T}}$, which is reported to be a very effective DZN transforming strain [38]

To verify the capability of D-G6 for transforming DZN, D-G6 was incubated with DZN at $37^{\circ} \mathrm{C}$ under anaerobic conditions and the products were detected using HPLC and Q-TOF-MS. Both DZE ${ }^{\mathrm{T}}$ and D-G6 converted DZN (5.2 $\mathrm{min}$ ) to EQL (6.2 $\mathrm{min}$ ) and DHD (4.2 $\mathrm{min}$ ) following $2 \mathrm{~d}$ of incubation (Figure $4 \mathrm{a}-\mathrm{d}$ ). The $4.2 \mathrm{~min}$ product was verified using Q-TOF-MS (Figure 4e,f). When incubation time was prolonged to $3 \mathrm{~d}$, both D-G6 and DZE ${ }^{\mathrm{T}}$ completely transformed DZN into EQL (Figure 4g, h).

The capacity of D-G6 and DZE ${ }^{\mathrm{T}}$ was further compared at increasing DZN concentrations. Both D-G6 and DZE ${ }^{\mathrm{T}}$ transformed over $90 \%$ of $0.6 \mathrm{M} \mathrm{DZN}$ to EQL after $3 \mathrm{~d}$ of incubation (Table 2). When the concentration was increased to $2 \mathrm{M}$, both D-G6 and DZE ${ }^{\mathrm{T}}$ transformed approximately $50 \%$ of $2 \mathrm{M}$ DZN to EQL after $3 \mathrm{~d}$ of incubation (Table 2). Altogether, the efficiency displayed by D-G6 for DZN transforming, was comparable to that of the well-known DZN transforming strain, DZE ${ }^{\mathrm{T}}$.

Table 2. Comparison of the efficiencies of D-G6 and DZE ${ }^{\mathrm{T}}$ for transforming DZN to EQL.

\begin{tabular}{cccccccc}
\hline \multirow{2}{*}{ DZN (M) } & \multirow{2}{*}{ Time (d) } & \multicolumn{3}{c}{ D-G6 } & \multicolumn{3}{c}{ DZE $^{\text {T }}$} \\
\cline { 3 - 8 } & & DHD (\%) & DZN (\%) & EQL (\%) & DHD (\%) & DZN (\%) & EQL (\%) \\
\hline \multirow{2}{*}{0.2} & 2 & $5-30$ & $0-10$ & $60-100$ & $0-18$ & $0-6$ & $89-100$ \\
& 3 & $0-5$ & 0 & $>97$ & $0-6$ & 0 & $>90$ \\
\hline \multirow{2}{*}{0.6} & 2 & $10-30$ & $30-40$ & $32-52$ & $8-18$ & $10-19$ & $60-76$ \\
& 3 & $4-9$ & $<5$ & $>90$ & 0 & $<5$ & $>95$ \\
\hline \multirow{2}{*}{2} & 2 & $3-15$ & $68-80$ & $10-19$ & $2-10$ & $60-78$ & $14-25$ \\
& 3 & $8-15$ & $20-35$ & $50-60$ & $5-10$ & $25-40$ & $55-65$ \\
\hline
\end{tabular}

Note: $10^{7}-10^{8} \mathrm{CFU} / \mathrm{mL}$ of D-G6 or DZE ${ }^{\mathrm{T}}$ were inoculated into $0.2 \mathrm{~mL}$ WCA modified medium. The conditions for incubation were as follows: $37^{\circ} \mathrm{C}, \mathrm{pH}$ 7.2. All experiments were repeated at least 3 times independently. 
a

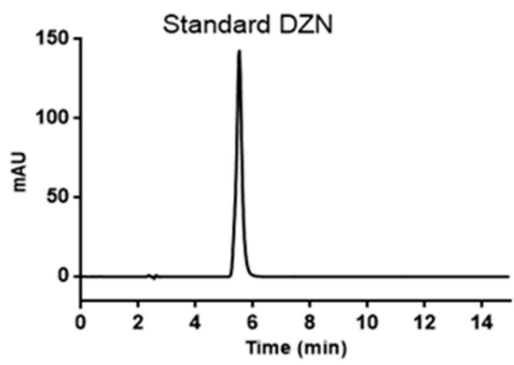

c

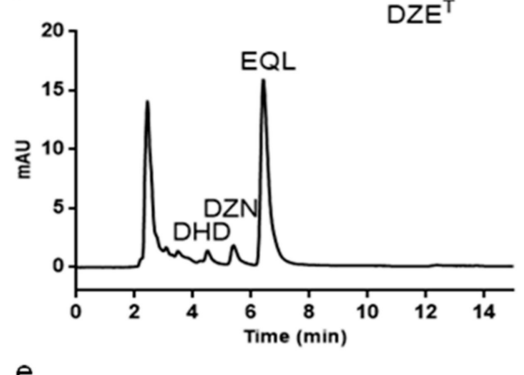

b

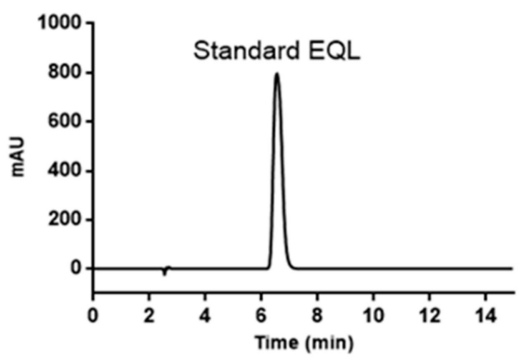

d

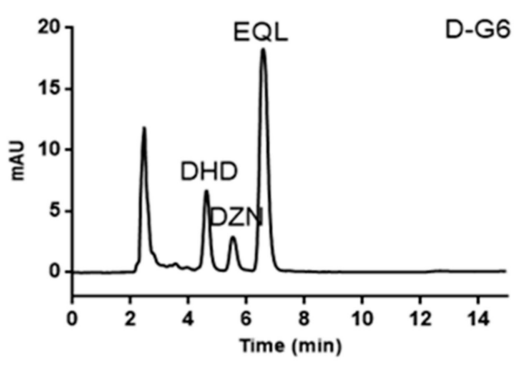

e

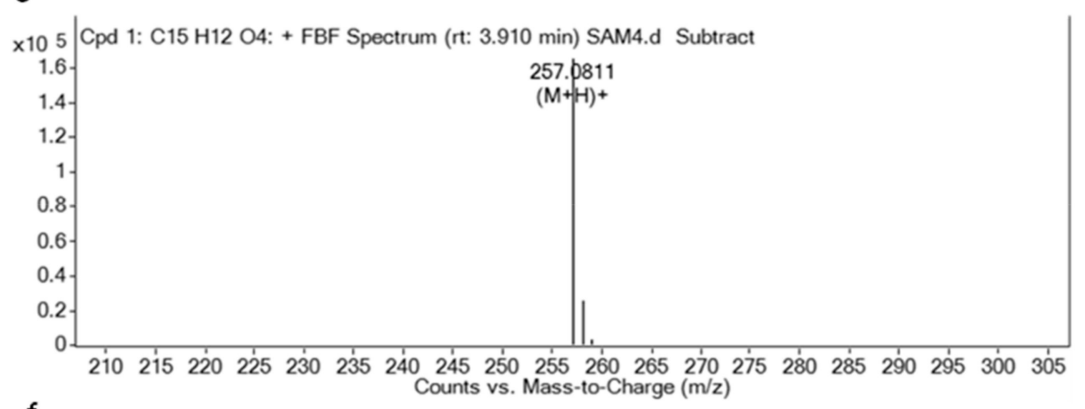
f

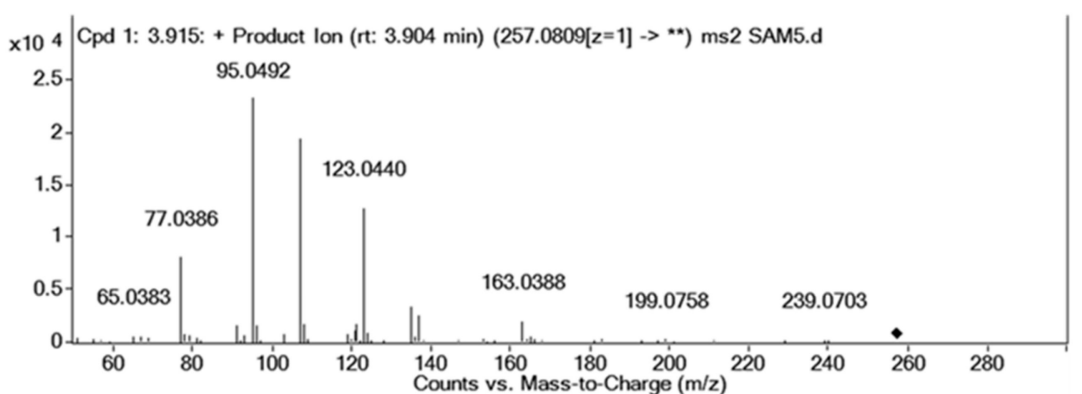

g

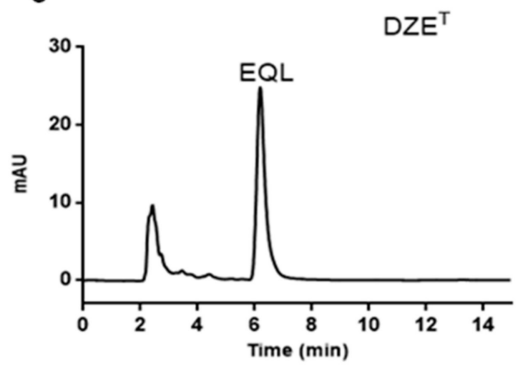

$\mathrm{h}$

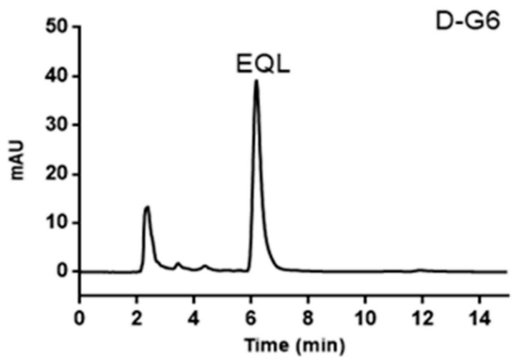

Figure 4. Slackia sp. D-G6 is capable of transforming daidzein (DZN). (a,b). DZN standards (a) and equol (EQL) (b). The retention time of DZN and EQL were approximately $5.2 \mathrm{~min}$ and $6.2 \mathrm{~min}$, respectively. (c,d). HPLC analysis of the products after $2 \mathrm{~d}$ of incubation of DZE ${ }^{\mathrm{T}}$ (c) or D-G6 (d) with DZN. (e,f). Mass spectrometry (e) and mass/mass spectrometry (f) analysis of the product at $4.2 \mathrm{~min}$. g,h. HPLC analysis of the products after $3 \mathrm{~d}$ of incubation with DZE ${ }^{\mathrm{T}}$ (g) or D-G6 (h) with DZN. 


\subsection{Characteristics of the D-G6 Genome and Genes Potentially Involved in DON De-Epoxidation}

In order to understand molecular mechanisms underlying DON de-epoxidation, the genome of D-G6 was sequenced and compared to reference genomes of DZE ${ }^{\mathrm{T}}$. The genome of DG-6 is 2,863,556-bp long (Figure 5a), with G + C content of $60.48 \%, 2312$ predicted protein coding genes, 29 rRNA genes, and 47 tRNA genes (Table 3).
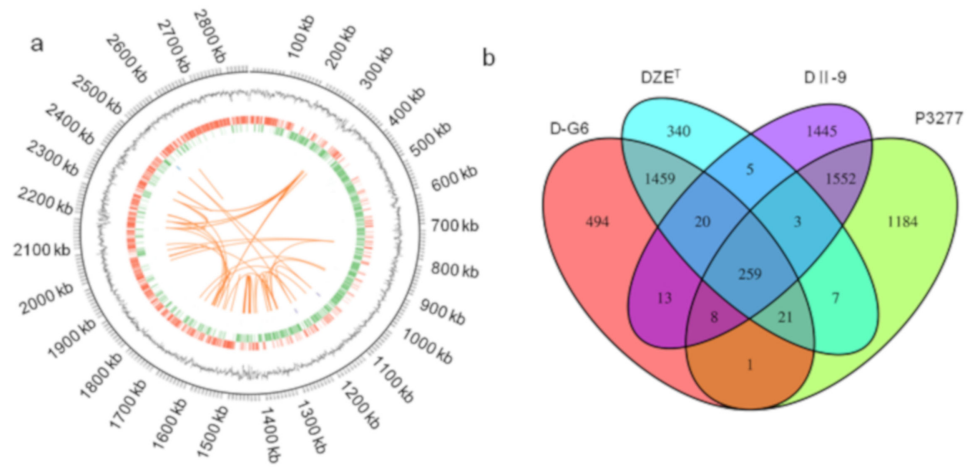

Figure 5. The genome of Slackia sp. D-G6 and comparative analysis of four genomes, D-G6, DZE ${ }^{\mathrm{T}}$, DII-9, and P3277. (a). The genome circle map was drawn using Circos (version 0.69) software. Seven types of information are contained in the circle diagram, from outside to inside: the first circle shows the size of the genome, the second one is GC content, the third one are coding genes on the positive chain (red), the fourth one are the coding genes on the negative chain (green), the fifth and sixth ones are ncRNA on positive strand (blue) and negative strand (purple) respectively, and the seventh one are the repeating sequences of long segments within the genome (orange). (b). Venn diagram showing the core genes and genes shared among D-G6, DII-9, DZE ${ }^{\mathrm{T}}$, and P3277.

Table 3. Genome comparison between D-G6 and DZE ${ }^{\mathrm{T}}$.

\begin{tabular}{ccc}
\hline & D-G6 & DZE $^{\mathbf{T}}$ \\
\hline Size $(\mathrm{Mb})$ & 2.86 & 2.75 \\
$\mathrm{G}+\mathrm{C}(\%)$ & 60.48 & 59.8 \\
Total number of & 2312 & 2149 \\
protein-coding genes & 29 & 10 \\
Total number of rRNA genes & 47 & 47 \\
Total number of tRNA genes & & \\
\hline
\end{tabular}

To predict the genes potentially involved in DON de-epoxidation, a genome comparison was made between two bacteria capable of DON de-epoxidation (D-G6 and DII-9) and closely related strains which showed no DON de-epoxidation activity $\mathrm{DZE}^{\mathrm{T}}$ and Raoultibacter timonensis P3277 (P3277), respectively. Thirteen clusters were identified as homologous genes between D-G6 and DII-9 that may be involved in DON de-epoxidation (purple color, Figure 5b). The functions of these 13 clusters were predicted and listed (Table 4). Among the 13 genes, two clusters (cluster 892 and 2459) with predicted redox activity and three clusters (cluster 4328, 4382, and 6747) with predicted unknown function were recombinantly expressed and analyzed for DON de-epoxidation activity in vitro. However, all five chosen clusters did not display DON de-epoxidation activity in vitro (data now shown), suggesting that de-epoxidation is a complex process, which may involve multiple enzymes and require special reaction conditions. 
Table 4. The list of 13 clusters that may be critical for DON de-epoxidation.

\begin{tabular}{|c|c|c|c|}
\hline Clusters & Predicted Functions & $\begin{array}{l}\text { cds Number } \\
\text { of D-G6 }\end{array}$ & $\begin{array}{l}\text { cds Number } \\
\text { of D II-9 }\end{array}$ \\
\hline Cluster-761 & potassium-transporting ATPase activity & cds-765 & cds-727 \\
\hline Cluster-892 & FAD-binding dehydrogenase & cds-1661 & cds-605 \\
\hline Cluster-1703 & ISL3 family transposase & cds-1137/1145/1147/1172/1175 & cds-1991/1993 \\
\hline Cluster-2351 & IS256 family transposase & cds-761/1023/1046 & cds-1169/1999 \\
\hline Cluster-2392 & ring-opening amidohydrolase & cds- 1648 & cds-1300 \\
\hline Cluster-2459 & $\begin{array}{l}\text { catalytic activity | iron-sulfur } \\
\text { cluster binding }\end{array}$ & cds-1695 & cds-795 \\
\hline Cluster-3749 & aminoglycoside $3^{\prime}$-phosphotransferase III & cds-1146 & cds-1992 \\
\hline Cluster-3864 & $\begin{array}{l}\text { aminoglycoside } 3^{\prime \prime} \text {-adenylyltransferase } \\
\text { activity| response to antibiotic }\end{array}$ & cds-2270 & cds-1167 \\
\hline Cluster-4013 & dimethyladenosine transferase & cds-1144 & cds-1932 \\
\hline Cluster-4328 & protein of unknown function & cds-1907 & cds-1995 \\
\hline Cluster-4382 & hypothetical protein & cds-2273 & cds-1837 \\
\hline Cluster-6654 & isoleucyl-tRNA synthetase & cds-1205 & cds-928 \\
\hline Cluster-6747 & protein of unknown function & cds-2271 & cds-1166 \\
\hline
\end{tabular}

\section{Discussion}

Widespread, heavy contamination by DON, has posed a serious threat to the animal feed industry as well as the food industry for a long time. Currently, bio-transformation is considered the most promising strategy for detoxifying DON. The current study identified a novel bacterium, D-G6, capable of DON de-epoxidation. In addition to its role in DON de-epoxidation, D-G6 actively produces a natural estrogen analogue, EQL.

De-epoxidation is one of the most important processes associated with DON detoxification. Previously, we isolated a bacterium, DII-9, which was effective for DON de-epoxidation [33]. Efforts to screen enzymes responsible for DON de-epoxidation in DII-9 have ended in failure. Therefore, we attempted to screen more bacteria, which are capable of DON de-epoxidation, and screened associated enzymes using comparative genomics. As a result, one novel bacterium, D-G6 was identified. Except for DG-6 and DII-9, 3 other bacteria, BBSH797 from bovine rumen [32], LS100 from chicken intestine [31], and Clostridium sp. WJ06 (WJ06) from animal intestine [39] have been identified as capable of DON de-epoxidation. BBSH797 belongs to the family Coriobacteriaceae. DII-9 and D-G6 belong to the family Eggerthellaceae. Interestingly, Coriobacteriaceae and Eggerthellaceae belong to the same order, Coriobacteriales, suggesting a connection with DON de-epoxidation. However, genome data of BBSH797, LS100, and WJ06 have not yet been revealed, causing difficulties in identifying the enzymes possibly involved in DON de-epoxidation via comparative genomics.

The genome data of four strains were compared. Of these, DG-6 and DII-9, display DON de-epoxidation activity. The other two, $\mathrm{DZE}^{\mathrm{T}}$, and P3277, which are the strains closest to DG-6 and DII-9, respectively, do not display DON de-epoxidation activity. Thirteen clusters, which are likely involved in DON de-epoxidation were identified (Table 4), five of which were recombinantly expressed and tested. However, all five chosen clusters did not display DON de-epoxidation in vitro (data now shown), suggesting that de-epoxidation is a complex process. The cds-1661 and cds-605 from D-G6 and DII-9, respectively, were annotated as FAD-binding dehydrogenases, and upstream and downstream genes of cds-1695 and cds-795 were FAD oxidoreductases (data not shown, concluded from gene annotations), suggesting that FAD may play a role in DON de-epoxidation. Interestingly, de-epoxidation efficiency increased over 50\% when 1 mM FAD, NADPH, or NADH was added to the reaction system comprised of D-G6 membrane components (data not shown), suggesting that the de-epoxidation may be a redox process involving FAD, NADPH, and/or NADH.

Reportedly, strains of genus Slackia have transformed isoflavones effectively. Metabolites of isoflavones are beneficial for human and animal health, and generally function more effectively than their precursors [40-42]. Isoflavones mainly contain DZN and genistein, which are present in soybeans 
and other Fabaceae. Because of structural similarities between isoflavones and endogenous estrogens, isoflavones and their metabolites are able to bind estrogen receptors and exert hormonal effects, including anti-oxidative, anti-inflammatory [43], and anti-tumor cell proliferation [44]. When DZN is incubated with D-G6, DZN is effectively degraded into DHD and EQL within 2 days. If incubation occurs for 3 days, complete degradation into EQL is observed (Figure 4 and Table 2). These results indicated that D-G6 activity is comparable to the well-known isoflavone degradation strain $\mathrm{DZE}^{\mathrm{T}}$ [38]. Clinically, approximately $30 \%$ to $50 \%$ of humans have the ability to produce EQL from ingested DZN via intestinal bacteria [45].

\section{Conclusions}

In summation, the current study has revealed, for the first time, a dual function bacterium, Slackia sp. D-G6, that is active in DON detoxification and EQL production, providing a good resource, which can be used to enhance feed and food additives. D-G6 was a Gram-positive non-sporulating bacterium varying from $0.2-0.4 \mu \mathrm{m} \times 0.6-1.0 \mu \mathrm{m}$. The optimum conditions for D-G6 to transform DON were within $37-47^{\circ} \mathrm{C}$ and $\mathrm{pH} 6-10$.

\section{Materials and Methods}

\subsection{Materials}

DON and DOM-1 were purchased from Pribolab (Beijing, China) and Sigma-Aldrich (St. Louis, MO, USA), respectively. Daidzein and equol were purchased from ADOOQ (Irvine, CA, USA) and SellckChem (Houston, TX, USA), respectively. Acetonitrile (HPLC grade) was obtained from CNW Technologies (Duesseldorf, Germany). Brain heart infusion was purchased from Thermo Fisher Oxoid (Altrincham, England). NB, GAM, WCA, TSB, and Columbia were all obtained from Qingdao haibo biology company (Qingdao, China).

\subsection{Bacterium Screening Methods}

One gram of feces from chicken intestines was mixed with $1 \mathrm{ml} \mathrm{BHI} \mathrm{broth} \mathrm{to} \mathrm{produce} \mathrm{a}$ homogeneous mixture. The mixture $(20 \mu \mathrm{L})$ was inoculated with $180 \mu \mathrm{L}$ fresh of BHI and $25 \mu \mathrm{g} / \mathrm{mL}$ of DON, and incubated at $37^{\circ} \mathrm{C}$ under anaerobic conditions. The total concentration of DON used in this study was $25 \mu \mathrm{g} / \mathrm{mL}$ unless otherwise specified. DON and its product DOM- 1 were detected $3 \mathrm{~d}$ following incubation using HPLC. Cultures with transforming rates over 50\% were selected as samples for subsequent screening. Selected cultures were freshly inoculated with dilution of $10-10^{6}$ fold in series. Subsequently, cultures with transformation rates $>50 \%$ and inoculation densities lower than $10^{3} \mathrm{CFU} / \mathrm{ml}$ were selected as samples for the next screening iteration. Single colonies were isolated from $\mathrm{BHI}$ agar and their activity was confirmed. Culture media were then screened to improve the activity of colonies that showed DON transforming ability. NB, GAM, WCA, TSB, and Columbia with or without chicken intestinal extract (Ext) were analyzed.

\subsection{Extraction and Analysis of DON and DOM-1}

Detection of DON and DOM-1 has been described previously [33]. In brief, after $3 \mathrm{~d}$ of incubation, 3 times the volume of ethyl acetate was added to the culture and the resultant mixture was subjected to vibration for $1 \mathrm{~min}$. The supernatant was evaporated using a stream of highly pure nitrogen, until dry. Next, $25 \%$ methanol $(200 \mu \mathrm{L})$ was added to dissolve the dried samples. Extracted samples were detected via HPLC using previously described [33].

\subsection{Comparing the Transforming Rate under Different Culture Media, Temperatures and $p H$}

Five basic media (BHI, NB, GAM, WCA, and TSB) and their modified forms (addition of 50\% Ext) were analyzed. Aliquots $(2 \mu \mathrm{L})$ of the Slackia sp. D-G6 (D-G6) culture sample were transferred to $0.2 \mathrm{ml}$ of medium, and incubated under anaerobic conditions for 3 days. Following incubation, 
DON and DOM-1 were extracted and analyzed using HPLC. The transforming rate was calculated as DOM-1/DON+DOM-1 in all experiments.

Six temperature, $27,32,37,42,47$, and $52^{\circ} \mathrm{C}$, and $9 \mathrm{pH}$ conditions, $3,4,5,6,7,8,9,10$, and 11 were analyzed. D-G6 was inoculated into $0.2 \mathrm{ml}$ WCA medium plus $50 \%$ Ext at an initial density of $10^{7}-10^{8}$ $\mathrm{CFU} / \mathrm{mL}$. The samples were incubated under anaerobic conditions for 3 days. Following incubation, the DON and DOM-1 were extracted and analyzed. Curves of growth and metabolic activity vs. time were analyzed in WCA medium plus $50 \%$ Ext, under $37^{\circ} \mathrm{C}$ and $\mathrm{pH} 6.5$.

\subsection{Phylogenetic Tree Construction}

The 16S rDNA of D-G6 was amplified using primers 27f and 1492r [38,46]. BLAST analysis available at the National Center for Biotechnology Information (NCBI) database was used to analyze the sequence similarity (https://blast.ncbi.nlm.nih.gov/Blast.cgi?PROGRAM=blastn\&PAGE_TYPE=BlastSearch\& LINK_LOC=blasthome). Sequences that were either phylogenetically closest or functionally similar were downloaded. The phylogenetic tree was constructed using MEGA 6 software [47]. Bootstrap values were calculated based on 1000 re-samplings via the neighbor-joining method.

\subsection{Morphologic Analysis}

Morphology was analyzed via gram staining and Transmission Electron Microscopy (TEM). Following gram staining, an optical microscope with 100× oil immersion was used to observe bacterial cells revived in BHI agar for 1-2 days. Bacteria in the logarithmic phase were washed with PBS and fixed using phosphomolybdic acid. Subsequently, the size and morphology of D-G6 were observed using TEM (Tecnai 12, FEI company, Eindhoven, Netherlands).

\subsection{Genome Sequencing}

The genome of D-G6 was sequenced by GENEWIZ incorporated company (Shenzhen, China). One hundred nanograms of D-G6 genomic DNA was randomly fragmented to $<500 \mathrm{bp}$ via sonication (Covaris S220). The fragments were modified via $5^{\prime}$ phosphorylation and dA-tailing. Next, adaptors were added to both ends after the fragments. Fragments of $\sim 470 \mathrm{bp}$ were purified by size based selection of adaptor-ligated DNA. The library was amplified via PCR for 8 cycles using primers P5 and P7. Following clean up and validation using an Agilent 2100 Bioanalyzer (Agilent Technologies, Palo Alto, CA, USA) and quantified by Qubit 3.0 Fluorometer (Invitrogen, Carlsbad, CA, USA), sequencing was carried out using a $2 \times 150$ paired-end (PE) configuration and monitored by the HiSeq Control Software (HCS) + OLB + GAPipeline-1.6 (Illumina) (San Diego, CA, USA) on a HiSeq instrument and processed via image analysis and base calling.

For analysis performed by Pacbio (Menlo Park, CA, USA), the construction of the SMRTbell library required $10 \mathrm{~kb}$ double-stranded DNA fragments end repaired and ligated with universal hairpin adapters. The library was sequenced in a PacBio RSII/Sequel SMRT instrument [48]. PacBio reads were assembled using HGAP4/Falcon WGS-Assembler 8.2 [49], and re-corrected through either Pilon software using previous Illumina data or Quiver using Pacbio reads.

\subsection{Drawing the Genome Circle Map}

The genome circle map was drawn by using of Circos (version 0.69, Genome Sciences Centre, Vancouver, BC, Canada) software. A circle diagram, containing 7 rings, of the D-G6 genome. The first circle shows the size of the genome, the second circle represents GC content, the third circle shows coding genes on the positive strand (red), the fourth circle shows coding genes on the negative strand (green), the fifth and sixth circles represent ncRNA on the positive strand (blue) and the negative strand (purple), respectively and the seventh circle presents information on repeating sequences of long segments within the genome (orange). 


\subsection{Comparing the Activity of Slackia sp. D-G6 and Slackia equolifaciens Strain DZE ${ }^{T}\left(D Z E^{T}\right)$ on Transforming Daidzein (DZN)}

D-G6 and DZET were inoculated into the medium (WCA+ 50\% intestine extract) treated with $0.2 \mathrm{M} \mathrm{DZN}$, and incubated under anaerobic conditions at $37^{\circ} \mathrm{C}$. Following a 3 days incubation period, ethyl acetate $(600 \mu \mathrm{L})$ was added to stop the reaction following which the product was vortexed vigorously. The organic phase was separated and transferred to a new Eppendorf tube, vacuum dried, and dissolved in $0.2 \mathrm{ml}$ of methanol. Extracted samples were analyzed via HPLC and UPLC-Q-TOF-MS to quantify levels of DZN and its potential metabolites [50]. Metabolites were analyzed using a C18 reverse column $(5 \mu \mathrm{m}, 4.6 \times 250 \mathrm{~mm})$ with an isocratic mobile phase comprising, $45 \%$ water: acetic acid $(98: 2, v / v)$ in methanol $\left(1 \mathrm{~mL} / \mathrm{min}, 40^{\circ} \mathrm{C}\right)$ with detection at $280 \mathrm{~nm}$ [50]. For UPLC-Q-TOF-MS, an Agilent Eclipse plus C18 $(1.8 \mu \mathrm{m}, 50 \mathrm{~mm} \times 2.1 \mathrm{~mm})$ was used, and the mobile phase was comprised of $60 \%$ water: formic acid $(98: 0.2, v / v)$ in methanol $(0.3 \mathrm{~mL} / \mathrm{min})$. Gas temperature was $300{ }^{\circ} \mathrm{C}$ with $8 \mathrm{~L} / \mathrm{min}$ gas flow.

\section{Patents}

There is a patent on pending.

Author Contributions: Y.D., X.G., P.M., and J.W. conceived and designed the experiments; X.G., X.Z., Y.W., X.M., and X.W. performed the experiments; X.G. and P.M. analyzed the data; X.G., P.M., X.C., and S.T. wrote the paper. All authors have read and agreed to the published version of the manuscript.

Funding: This research was funded by the National Key Research and Development Program of China [2016YFD0501201], the Natural Science Foundation of Guangdong Province [2015A030312005], the Science and Technology Program of Guangzhou [201804020067], and the Department of Education of Guangdong Province [2017KCXTD001, 2018KZDXM015].

Conflicts of Interest: The authors declare no conflict of interest

\section{References}

1. Irakli, M.N.; Skendi, A.; Papageorgiou, M.D. HPLC-DAD-FLD Method for Simultaneous Determination of Mycotoxins in Wheat Bran. J. Chromatogr. Sci. 2017, 55, 690-696. [CrossRef] [PubMed]

2. Streit, E.; Naehrer, K.; Rodrigues, I.; Schatzmayr, G. Mycotoxin occurrence in feed and feed raw materials worldwide: long-term analysis with special focus on Europe and Asia. J. Sci. Food Agr. 2013, 93, 2892-2899. [CrossRef] [PubMed]

3. Neme, K.; Mohammed, A. Mycotoxin occurrence in grains and the role of postharvest management as a mitigation strategies. A review. Food Control 2017, 78, 412-425. [CrossRef]

4. Rotter, B.A.; Prelusky, D.B.; Pestka, J.J. Toxicology of deoxynivalenol (vomitoxin). J. Toxicol. Environ. Health 1996, 48, 1-34. [CrossRef] [PubMed]

5. Marin, S.; Ramos, A.J.; Cano-Sancho, G.; Sanchis, V. Mycotoxins: occurrence, toxicology, and exposure assessment. Food Chem. Toxicol. 2013, 60, 218-237. [CrossRef]

6. Wang, S.; Yang, J.; Zhang, B.; Wu, K.; Yang, A.; Li, C.; Zhang, J.; Zhang, C.; Rajput, S.A.; Zhang, N.; et al. Deoxynivalenol Impairs Porcine Intestinal Host Defense Peptide Expression in Weaned Piglets and IPEC-J2 Cells. Toxins 2018, 10, 541. [CrossRef]

7. Alshannaq, A.; Yu, J.H. Occurrence, Toxicity, and Analysis of Major Mycotoxins in Food. Inter. J. Env. Res. Pub. Heal. 2017, 14, 632. [CrossRef]

8. Uzarski, R.L.; Islam, Z.; Pestka, J.J. Potentiation of trichothecene-induced leukocyte cytotoxicity and apoptosis by TNF-alpha and Fas activation. Che. Biol. Interact. 2003, 146, 105-119. [CrossRef]

9. Pestka, J.J.; Zhou, H.R.; Moon, Y.; Chung, Y.J. Cellular and molecular mechanisms for immune modulation by deoxynivalenol and other trichothecenes: unraveling a paradox. Toxicol. letters 2004, 153, 61-73. [CrossRef]

10. Cundliffe, E.; Cannon, M.; Davies, J. Mechanism of inhibition of eukaryotic protein synthesis by trichothecene fungal toxins. PNAS 1974, 71, 30-34. [CrossRef]

11. Cundliffe, E.; Davies, J.E. Inhibition of initiation, elongation, and termination of eukaryotic protein synthesis by trichothecene fungal toxins. Antimicrob. Agents Chemother. 1977, 11, 491-499. [CrossRef] [PubMed] 
12. Chung, Y.J.; Zhou, H.R.; Pestka, J.J. Transcriptional and posttranscriptional roles for p38 mitogen-activated protein kinase in upregulation of TNF-alpha expression by deoxynivalenol (vomitoxin). Toxicol. Appl. Pharmacol. 2003, 193, 188-201. [CrossRef]

13. Pestka, J.J. Deoxynivalenol-induced proinflammatory gene expression: mechanisms and pathological sequelae. Toxins 2010, 2, 1300-1317. [CrossRef] [PubMed]

14. Moon, Y.; Pestka, J.J. Vomitoxin-induced cyclooxygenase-2 gene expression in macrophages mediated by activation of ERK and p38 but not JNK mitogen-activated protein kinases. Toxicol. Sci. 2002, 69, 373-382. [CrossRef]

15. Katika, M.R.; Hendriksen, P.J.; Shao, J.; van Loveren, H.; Peijnenburg, A. Transcriptome analysis of the human T lymphocyte cell line Jurkat and human peripheral blood mononuclear cells exposed to deoxynivalenol (DON): New mechanistic insights. Toxicol. Appl. Pharmacol. 2012, 264, 51-64. [CrossRef]

16. Schmeits, P.C.; Katika, M.R.; Peijnenburg, A.A.; van Loveren, H.; Hendriksen, P.J. DON shares a similar mode of action as the ribotoxic stress inducer anisomycin while TBTO shares ER stress patterns with the ER stress inducer thapsigargin based on comparative gene expression profiling in Jurkat $\mathrm{T}$ cells. Toxicol. letters 2014, 224, 395-406. [CrossRef]

17. Bensassi, F.; Gallerne, C.; Sharaf El Dein, O.; Lemaire, C.; Hajlaoui, M.R.; Bacha, H. Involvement of mitochondria-mediated apoptosis in deoxynivalenol cytotoxicity. Food Chem. Toxicol. 2012, 50, 1680-1689. [CrossRef]

18. Ma, Y.; Zhang, A.; Shi, Z.; He, C.; Ding, J.; Wang, X.; Ma, J.; Zhang, H. A mitochondria-mediated apoptotic pathway induced by deoxynivalenol in human colon cancer cells. Toxicol. 2012, 26, 414-420. [CrossRef]

19. Ostry, V.; Malir, F.; Toman, J.; Grosse, Y. Mycotoxins as human carcinogens-the IARC Monographs classification. Mycotoxin Res. 2017, 33, 65-73. [CrossRef]

20. Matarese, F.; Sarrocco, S.; Gruber, S.; Seidl-Seiboth, V.; Vannacci, G. Biocontrol of Fusarium head blight: interactions between Trichoderma and mycotoxigenic Fusarium. Microbiology 2012, 158, 98-106. [CrossRef]

21. Mandala, G.; Tundo, S.; Francesconi, S.; Gevi, F.; Zolla, L.; Ceoloni, C.; D’Ovidio, R. Deoxynivalenol Detoxification in Transgenic Wheat Confers Resistance to Fusarium Head Blight and Crown Rot Diseases. MPMI 2019, 32, 583-592. [CrossRef] [PubMed]

22. Berthiller, F.; Dall'Asta, C.; Schuhmacher, R.; Lemmens, M.; Adam, G.; Krska, R. Masked mycotoxins: determination of a deoxynivalenol glucoside in artificially and naturally contaminated wheat by liquid chromatography-tandem mass spectrometry. J. Agr. Food Chem. 2005, 53, 3421-3425. [CrossRef] [PubMed]

23. Kluger, B.; Bueschl, C.; Lemmens, M.; Michlmayr, H.; Malachova, A.; Koutnik, A.; Maloku, I.; Berthiller, F.; Adam, G.; Krska, R.; et al. Biotransformation of the mycotoxin deoxynivalenol in fusarium resistant and susceptible near isogenic wheat lines. PloS One 2015, 10, e0119656. [CrossRef] [PubMed]

24. Völkl, A.; Vogler, B.; Schollenberger, M.; Karlovsky, P. Microbial detoxifcation of mycotoxin deoxynivalenol. J. Basic. Microbiol. 2014, 44, 147-156.

25. Ikunaga, Y.; Sato, I.; Grond, S.; Numaziri, N.; Yoshida, S.; Yamaya, H.; Hiradate, S.; Hasegawa, M.; Toshima, H.; Koitabashi, M.; et al. Nocardioides sp. strain WSN05-2, isolated from a wheat feld, degrades deoxynivalenol, producing the novel intermediate 3-epi-deoxynivalenol. Appl. Microbiol. Biotechnol. 2011, 89, 419-427. [CrossRef]

26. He, W.; Zhang, L.; Yi, S.; Tang, X.; Yuan, Q.; Guo, M.; Wu, A.; Qu, B.; Li, H.; Liao, Y. An aldo-keto reductase is responsible for fusarium toxin-degrading activity in a soil sphingomonas strain. Sci. Rep. 2017, 7, 9549. [CrossRef]

27. Hassan, Y.I.; Lepp, D.; He, J.; Zhou, T. Draf genome sequences of Devosia sp. strain 17-2-E-8 and Devosia ribofavina strain IFO13584. Genome Announc. 2014, 2, e00994-14. [CrossRef]

28. Ito, M.; Sato, I.; Ishizaka, M.; Yoshida, S.-I.; Koitabashi, M.; Yoshida, S.; Tsushima, S. Bacterial cytochrome P450 system catabolizing the Fusarium toxin deoxynivalenol. Appl. Environ. Microbiol. 2013, 79, 1619-1628. [CrossRef]

29. Sundstol Eriksen, G.; Pettersson, H.; Lundh, T. Comparative cytotoxicity of deoxynivalenol, nivalenol, their acetylated derivatives and de-epoxy metabolites. Food Chemical toxicology: international J. published British Industrial Biol. Res. Assoc. 2004, 42, 619-624. [CrossRef]

30. Pierron, A.; Mimoun, S.; Murate, L.S.; Loiseau, N.; Lippi, Y.; Bracarense, A.P.; Schatzmayr, G.; He, J.W.; Zhou, T.; Moll, W.D.; et al. Microbial biotransformation of DON: molecular basis for reduced toxicity. Sci. Rep. 2016, 6, 29105. [CrossRef] 
31. Yu, H.; Zhou, T.; Gong, J.; Young, C.; Su, X.; Li, X.Z.; Zhu, H.; Tsao, R.; Yang, R. Isolation of deoxynivalenoltransforming bacteria from the chicken intestines using the approach of PCR-DGGE guided microbial selection. BMC Microbiol. 2010, 10, 182. [CrossRef] [PubMed]

32. Fuchs, E.; Binder, E.M.; Heidler, D.; Krska, R. Structural characterization of metabolites after the microbial degradation of type A trichothecenes by the bacterial strain BBSH 797. Food Addit. Contam. 2002, 19, 379-386. [CrossRef] [PubMed]

33. Gao, X.; Mu, P.; Wen, J.; Sun, Y.; Chen, Q.; Deng, Y. Detoxification of trichothecene mycotoxins by a novel bacterium, Eggerthella sp. DII-9. Food Chem. Toxicol. 2018, 112, 310-319. [CrossRef] [PubMed]

34. Birt, D.F.; Hendrich, S.; Wang, W. Dietary agents in cancer prevention: flavonoids and isoflavonoids. Pharmacol. Therap. 2001, 90, 157-177. [CrossRef]

35. Geller, S.E.; Studee, L. Soy and red clover for mid-life and aging. Climacteric 2006, 9, 245-263. [CrossRef] [PubMed]

36. Scalbert, A.; Manach, C.; Morand, C.; Remesy, C.; Jimenez, L. Dietary polyphenols and the prevention of diseases. Crit. Rev. Food Sci. Nutr. 2005, 45, 287-306. [CrossRef]

37. Usui, T. Pharmaceutical prospects of phytoestrogens. Endocrine J. 2006, 53, 7-20. [CrossRef]

38. Jin, J.S.; Kitahara, M.; Sakamoto, M.; Hattori, M.; Benno, Y. Slackia equolifaciens sp. nov., a human intestinal bacterium capable of producing equol. Int. J. Syst. Evol. Microbiol. 2009, 1721-1724. [CrossRef]

39. Li, F.; Wang, J.; Huang, L.; Chen, H.; Wang, C. Effects of Adding Clostridium sp. WJ06 on Intestinal Morphology and Microbial Diversity of Growing Pigs Fed with Natural Deoxynivalenol Contaminated Wheat. Toxins 2017, 9, 383. [CrossRef]

40. Yanjing, X.; Xiumei, Y. Bioconversion of genistein to (-)-5-hydroxy-equol by a newly isolated cock intestinal anaerobic bacterium. J. Chin. Pharm. Sci. 2015, 24, 442-448. [CrossRef]

41. Tsuji, H.; Moriyama, K.; Nomoto, K.; Miyanaga, N.; Akaza, H. Isolation and characterization of the equol-producing bacterium Slackia sp. strain NATTS. Arch. Microbiol. 2010, 192, 279-287. [CrossRef] [PubMed]

42. Matthies, A.; Blaut, M.; Braune, A. Isolation of a human intestinal bacterium capable of daidzein and genistein conversion. Appl. Environ. Microbiol. 2009, 75, 1740-1744. [CrossRef] [PubMed]

43. Medjakovic, S.; Mueller, M.; Jungbauer, A. Potential health-modulating effects of isoflavones and metabolites via activation of PPAR and AhR. Nutrients 2010, 2, 241-279. [CrossRef] [PubMed]

44. Lyn-Cook, B.D.; Stottman, H.L.; Yan, Y.; Blann, E.; Kadlubar, F.F.; Hammons, G.J. The effects of phytoestrogens on human pancreatic tumor cells in vitro. Cancer letters 1999, 142, 111-119. [CrossRef]

45. Matthies, A.; Clavel, T.; Gutschow, M.; Engst, W.; Haller, D.; Blaut, M.; Braune, A. Conversion of daidzein and genistein by an anaerobic bacterium newly isolated from the mouse intestine. Appl. Environ. Microbiol. 2008, 74, 4847-4852. [CrossRef]

46. Chen, L.; Zhang, H.; Liu, G.; Sha, W. First report on the bacterial diversity in the distal gut of dholes (Cuon alpinus) by using $16 \mathrm{~S}$ rRNA gene sequences analysis. J. Appl. Gene. 2016, 57, 275-283. [CrossRef]

47. Tamura, K.; Dudley, J.; Nei, M.; Kumar, S. MEGA4: Molecular Evolutionary Genetics Analysis (MEGA) software version 4.0. Mol. Biol. Evol. 2007, 24, 1596-1599. [CrossRef]

48. McCarthy, A. Third generation DNA sequencing: pacific biosciences' single molecule real time technology. Chem. Biol. 2010, 17, 675-676. [CrossRef]

49. Myers, E.W.; Sutton, G.G.; Delcher, A.L.; Dew, I.M.; Fasulo, D.P.; Flanigan, M.J.; Kravitz, S.A.; Mobarry, C.M.; Reinert, K.H.; Remington, K.A.; et al. A whole-genome assembly of Drosophila. Science 2000, 287, 2196-2204. [CrossRef]

50. Kawada, Y.; Yokoyama, S.; Yanase, E.; Niwa, T.; Suzuki, T. The production of S-equol from daidzein is associated with a cluster of three genes in Eggerthella sp. YY7918. Biosci. Microbio. Food Health 2016, 35, 113-121. [CrossRef]

(C) 2020 by the authors. Licensee MDPI, Basel, Switzerland. This article is an open access article distributed under the terms and conditions of the Creative Commons Attribution (CC BY) license (http://creativecommons.org/licenses/by/4.0/). 